\title{
MoRPhological and Biochemical Responses to Gibberellic Acid in Magnolia $\times$ 'Spectrum’ in Vitro
}

\author{
AgnieszKa Wojtania $^{1 *}$, Edyta SkrzyPeK ${ }^{2}$, And Eleonora Gabryszewska ${ }^{1}$ \\ ${ }^{1}$ Research Institute of Horticulture, Konstytucji 3 Maja 1/3, Skierniewice, Poland \\ ${ }^{2}$ The F. Górski Institute of Plant Physiology, Polish Academy of Sciences, \\ Niezapominajek 21, Kraków, Poland
}

Received February 19, 2016; revision accepted June 5, 2016

\begin{abstract}
The total soluble sugar content and antioxidant enzyme activities were studied for the first time during axillary shoot formation in Magnolia $\times$ 'Spectrum' in vitro in response to BAP $\left(0.3 \mathrm{mg} \mathrm{l}^{-1}\right)$, different levels of gibberellic acid $\left(\mathrm{GA}_{3} ; 0.0,0.1,0.5,1.0 \mathrm{mg} \mathrm{l}^{-1}\right)$, sucrose $\left(20\right.$ and $\left.30 \mathrm{~g} \mathrm{l}^{-1}\right)$ and nitrogen salts $\left(\mathrm{KNO}_{3} / \mathrm{NH}_{4} \mathrm{NO}_{3} ; 100 / 100 \%\right.$ and $75 / 50 \%$ relative to MS medium). Among various $\mathrm{GA}_{3}$ and sucrose/nitrogen salts ratios, the most effective axillary multiplication (5.9 shoots/explant) and leaf formation (25.7 leaves per multiplied clumps) were obtained after addition of $\mathrm{GA}_{3}$ at $0.1 \mathrm{mg} \mathrm{l}^{-1}$ to a BAP medium containing $20 \mathrm{~g} \mathrm{l}^{-1}$ sucrose and reduced levels of nitrogen salts $\left(75 \% \mathrm{KNO}_{3}\right.$ and $50 \% \mathrm{NH}_{4} \mathrm{NO}_{3}$ ). The addition of $\mathrm{GA}_{3}$ to the BAP medium enhanced shoot formation by $36 \%$ and leaf formation by $27 \%$. The highest shoot formation capacity of $M . \times$ 'Spectrum' in vitro coincided with enhanced levels of soluble sugar and peroxidase (POD) activity. Increasing $\mathrm{GA}_{3}$ concentration from 0.1 to $1.0 \mathrm{mg} \mathrm{l}^{-1}$ in the above medium resulted in inhibition of shoot and leaf formation and a decrease in the soluble sugar content. The influence of $\mathrm{GA}_{3}$ on the activities of catalase (CAT) and POD depended on its concentration and the levels of sucrose and nitrogen salts in the medium. The highest increase in CAT and POD activities, that coincided with the enhanced shoot formation capacity of $M . \times$ 'Spectrum' in vitro, was observed after addition of $\mathrm{GA}_{3}$ to the medium containing high levels of sucrose and nitrogen salts.
\end{abstract}

Keywords: antioxidant enzymes, axillary shoot formation, soluble sugar accumulation, sucrose to nitrogen salt ratio

\section{INTRODUCTION}

Magnolias (Magnoliaceae) have long been popular ornamental plants, recommended for planting in gardens and urban green areas. Magnolia $\times$ 'Spectrum' was bred in the US National Arboretum in 1963 and is a cross between M. liliflora 'Nigra' and $M$. sprengeri 'Diva'. It is a medium-sized tree with a conical habit, valuable for its very large, tulip-shaped, deep red-purple flowers appearing before the leaves, and for high resistance to frost. Due to difficulties in propagation of magnolias by cutting or grafting, development and optimization of in vitro propagation methods is desirable.

Magnolias are most often propagated by activation of axillary buds, which guarantees high genetic stability of the obtained plant material. It has been reported that obtaining high activity of axillary buds is not easy and depends on many factors, including the composition of basal salts, plant growth regulators and the genotype (Biedermann, 1987; Kamenicka and Lanakova, 2000; Podwyszyńska et al., 2000; Parris et al., 2012; Sokolov et al., 2014). Our previous study showed that growth and development of $M . \times$ soulangiana 'Coates' in vitro was significantly influenced by the levels and ratio of cytokinin, sucrose and nitrogen salts in the MS medium (Wojtania et al., 2015). Among different magnolia cultivars grown in vitro, $M . \times$ 'Spectrum' is characterized by relatively low activity of axillary buds.

In many plant species, low activity of axillary buds is caused by the paradormancy phenomenon, also known as apical dominance or correlative inhibition. It is known that bud activity is regulated by various factors, including phytohormones, nutrients and temperature (Chae et al., 2006). Shoot branching is highly stimulated by cytokinin. However, sometimes cytokinin is not sufficient for bud outgrowth because other factors affect the competency

\footnotetext{
*Corresponding author, email: agnieszka.wojtania@inhort.pl
} 
for buds to respond to cytokinin (Dun et al., 2012). Other factors that are involved in the regulation of plant and bud dormancy are gibberellins (GAs) and sugars (Horvath et al., 2002; Chae et al., 2006). A positive effect of gibberellic acid $\left(\mathrm{GA}_{3}\right)$ on bud break has been observed in some woody plant species cultured in vitro, including Camelia japonica (Beretta and Eccher, 1987; Wojtania et al., 2011) and Vitex negundo (Sahoo and Chand, 1998). On the other hand, many genotypes responded negatively to exogenous GA application. For example, $\mathrm{GA}_{3}$ added to a cytokinin-medium inhibited shoot formation in Ricinus communis (Sujatha and Reddy, 1998), and induced leaf chlorosis and bud necrosis in Ficus carica (Fraguas et al., 2004). To our knowledge, there is no information on the influence of $\mathrm{GA}_{3}$ on axillary bud activity in magnolia.

It is believed that enhanced regeneration potential and shoot formation capacity correlate with increased activity of antioxidant enzymes (Mitrović et al., 2012). Plant hormones are known to be involved in antioxidant responses of many plants (Mýtinová et al., 2011). For example, an influence of exogenously applied cytokinin on catalase (CAT) and peroxidase (POD) activities has been observed in axillary multiplication of Pelargonium hortorum (Wojtania and Skrzypek, 2014), and adventitious shoot formation in Pinus strobus (Tang and Newton, 2005). So far there has been no information on the effect of $\mathrm{GA}_{3}$ on antioxidant enzyme activities in relation to magnolia shoot formation.

The present study was undertaken to clarify the role of $\mathrm{GA}_{3}$ in formation of shoots in Magnolia $\times$ 'Spectrum' in vitro. Morphological and biochemical responses of magnolia shoots grown in the presence of different concentration of $\mathrm{GA}_{3}$, sucrose and nitrogen salts were studied.

\section{MATERIALS AND METHODS}

\section{PLANT MATERIAL AND GROWTH CONDITIONS}

Shoot cultures of Magnolia $\times$ 'Spectrum' were initiated from apical and axillary bud explants, collected from two-year-old field-grown plants. The initial explants and the subsequent subcultures of axillary shoots were performed on Murashige and Skoog (1962) basal medium containing $100 \mathrm{mg} \mathrm{l}^{-1}$ myo-inositol, nicotinic acid, pyridoxine and thiamine (1.0 $\mathrm{mg} \mathrm{l}^{-1}$ each), $1.0-1.5 \mathrm{mg} \mathrm{l}^{-1}$ benzylaminopurine (BAP), $30 \mathrm{~g} \mathrm{l}^{-1}$ sucrose and solidified with $6.5 \mathrm{~g} \mathrm{l}^{-1}$ LAB-AGAR (Biocorp Poland). The $\mathrm{pH}$ of the medium was adjusted to 5.6 before autoclaving. The culture of axillary shoots was subcultured on a fresh medium every 5 weeks. After a few subcultures the shoots showed progressive hyperhydricity, as well as inhibited activity of axillary buds.

\section{SHOOT GROWTH AND DEVELOPMENT}

Single shoots harvested from shoot cultures were used as explants. The magnolia shoots were cultured on MS medium containing benzylaminopurine (BAP; $0.3 \mathrm{mg} \mathrm{l}^{-1}$ ) and different concentration of gibberellic acid $\left(\mathrm{GA}_{3} ; 0.0,0.1,0.5,1.0 \mathrm{mg} \mathrm{l}^{-1}\right)$, nitrogen salts $\left(\mathrm{KNO}_{3} / \mathrm{NH}_{4} \mathrm{NO}_{3} ; 100 / 100 \%\right.$ and $75 / 50 \%$ relative to the MS medium), and sucrose (20 and $30 \mathrm{~g} \mathrm{l}^{-1}$ ). The concentration of cytokinin was determined on the basis of previous experiments (Wojtania et al., 2015). Explants grown on a medium without $\mathrm{GA}_{3}$ were used as controls.

The shoot cultures were kept at $23^{\circ} \mathrm{C}$, under a 16/8 h day/night photoperiod provided by coolwhite fluorescent lamps at $40 \mu \mathrm{mol} \mathrm{m}{ }^{-2} \mathrm{~s}^{-1}$ (Philips TLD 36W/95). The single shoots were subcultured at 5-week intervals. Each treatment consisted of 25 explants. The experiment was repeated twice. The observations and measurements were recorded after 2 subcultures on the same medium. The number and length of the axillary shoots, the number of leaves and the number of brown leaves (\%) were determined. Leaf samples were also collected at that time for determination of the soluble sugar content as well as peroxidase (POD) and catalase (CAT) activities.

\section{ANALYSIS OF SOLUBLE SUGAR}

Soluble sugars in the leaves after homogenization were extracted with $1 \mathrm{ml}$ of $80 \%$ aqueous ethanol, then centrifuged at $2800 \mathrm{rpm}$ for $10 \mathrm{~min}$. The amount of total sugars was estimated by the phenol-sulfuric method (Dubois et al., 1956). The supernatant was mixed with $5 \%$ phenol and sulphuric acid. The absorbance $(\lambda=490 \mathrm{~nm})$ of the samples was measured spectrophotometrically on a micro-plate reader (Synergy 2, Bio-Tek, Winooski, VT, USA). The amounts of soluble sugars were expressed in milligrams (mg) per $1 \mathrm{~g}$ of fresh mass (FM) of plant tissue.

\section{ACTIVITY OF ANTIOXIDATIVE ENZYMES}

Plant tissue was homogenized at $4^{\circ} \mathrm{C}$ with a phosphate buffer ( $\mathrm{pH}$ 7.8) containing 0.01 M EDTA and $0.5 \% \mathrm{BSA}$. The homogenate was centrifuged at $2800 \mathrm{rpm}$ for $10 \mathrm{~min}$.

The activity of catalase (CAT, EC 1.11.1.6) was measured spectrophotometrically $(\lambda=240 \mathrm{~nm})$ by the modified method of Aebi (1984). The reaction mixture consisted of $200 \mu \mathrm{l} 0.05 \mathrm{M}$ phosphate buffer ( $\mathrm{pH}$ 7.0) containing $0.1 \mathrm{mM}$ EDTA, $50 \mu \mathrm{l}$ of $0.03 \mathrm{M} \mathrm{H}_{2} \mathrm{O}_{2}$ in this buffer and $5 \mu$ of the supernatant.

The activity of peroxidase (POD, EC 1.11.1.11) was measured by the modified method of Lück (1962). The measurement was carried out spectrophotometrically $(\lambda=460 \mathrm{~nm})$, by measuring in $300 \mu \mathrm{l}$ of $0.05 \mathrm{M}$ phosphate buffer containing 
$0.1 \mathrm{mM}$ EDTA, pH 7.0, the amount of the products of $5 \mu \mathrm{l}$ of $1 \% \mathrm{p}$-phenylenediamine and $5 \mu \mathrm{l}$ supernatant. The reaction was started in the presence of $5 \mu \mathrm{l}$ of $0.03 \mathrm{M} \mathrm{H}_{2} \mathrm{O}_{2}$.

The reaction kinetics for all the enzymes was examined spectrophotometrically on a microplate reader (Synergy 2, Bio-Tek, Winooski, VT, USA) after 60 and 120 s since the initiation of the reaction.

The data were subjected to a three factor analysis of variance in relation to exogenous $\mathrm{GA}_{3}$, nitrogen and sucrose treatments. The means were compared by Duncan's test at the $\alpha=0.05$ significance level.

\section{RESULTS}

\section{SHOOT GROWTH AND DEVELOPMENT}

The results of our study showed that the addition of $\mathrm{GA}_{3}$ to a BAP medium increased shoot and leaf formation in Magnolia $\times$ 'Spectrum' in vitro, but its effect on those processes significantly depended on the sucrose/nitrogen salt ratio in the MS medium (Fig. 1a and 2a). The most effective axillary multiplication and leaf formation was observed on the medium containing $20 \mathrm{~g} \mathrm{l}^{-1}$ sucrose and reduced levels of nitrogen salts $\left(75 \% \mathrm{KNO}_{3}\right.$ and $50 \%$ $\mathrm{NH}_{4} \mathrm{NO}_{3}$ relative to the MS medium). On this medium, $\mathrm{GA}_{3}$ applied together with BAP enhanced shoot formation in $M$. × 'Spectrum' by $36 \%$ and leaf formation by $27 \%$. The highest multiplication rate (5.9 shoots/explants) and the highest number of leaves (25.7 leaves per multiplied clumps) were obtained in the presence of $0.1 \mathrm{mg} \mathrm{l}^{-1} \mathrm{GA}_{3}$. Increasing GA concentration from 0.1 to $1.0 \mathrm{mg} \mathrm{l}^{-1}$ resulted in inhibition of shoot and leaf formation (Fig. 1a, 2a and 3). Lateral bud outgrowth was completely suppressed at $1.5 \mathrm{mg} \mathrm{l}^{-1} \mathrm{GA}_{3}$ (data not shown).

The development of $M$. × 'Spectrum' axillary shoots and leaves was significantly inhibited by sucrose at a concentration of $30 \mathrm{~g} \mathrm{l}^{-1}$ (Fig. 1a and $2 \mathrm{a})$. The sucrose-inhibition of shoot forma-
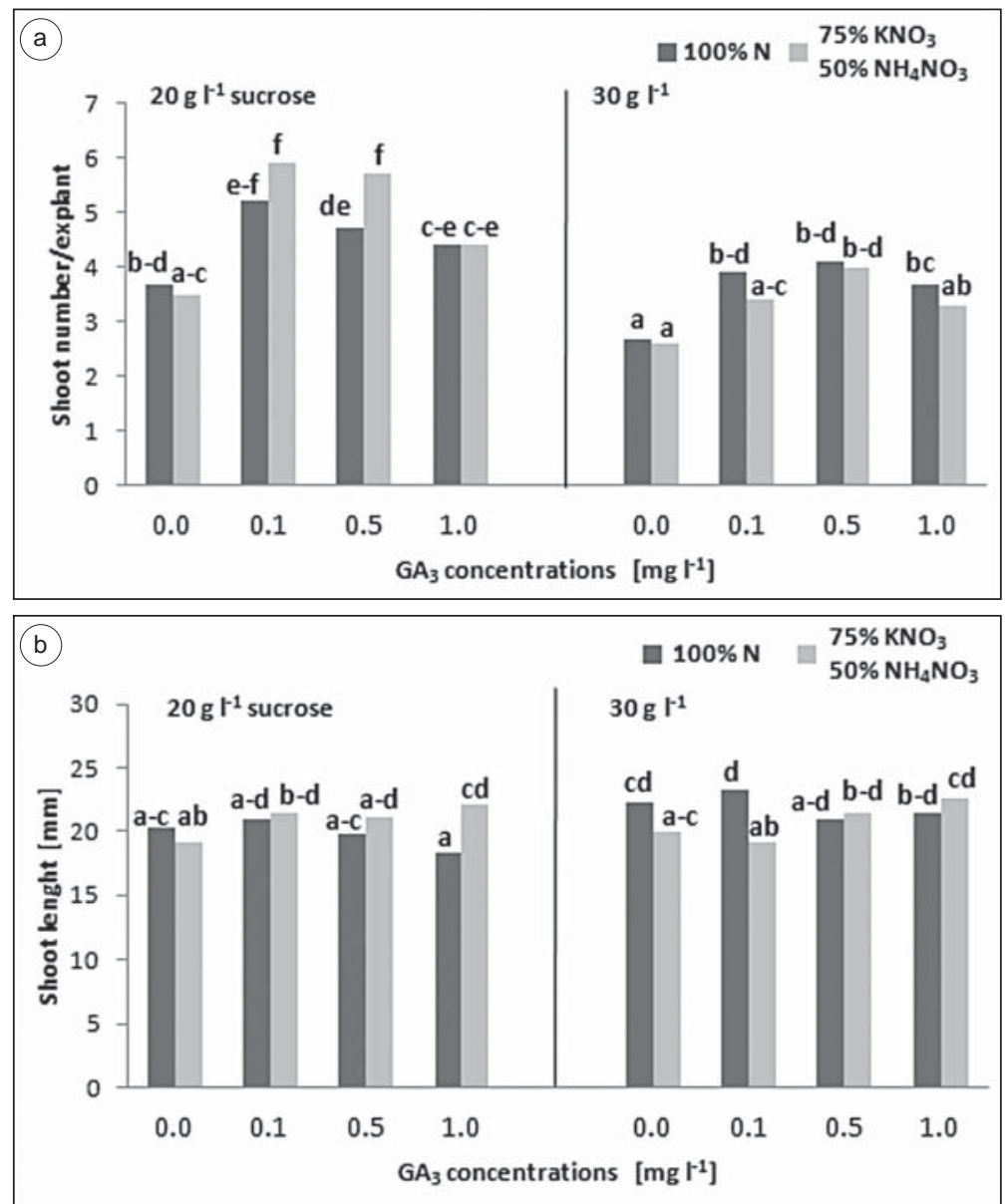

Fig. 1. Effect of $\mathrm{GA}_{3}$, added to MS medium containing BAP $\left(0.3 \mathrm{mg} \mathrm{l}^{-1}\right)$, different concentrations of sucrose and nitrogen salts on shoot formation (a) and shoot length (b) in M. $\times$ 'Spectrum' after a 5-week subculture period. Means of each growth parameter designated with the same letter do not differ significantly $(\alpha=0.05)$ according to Duncan's test. 

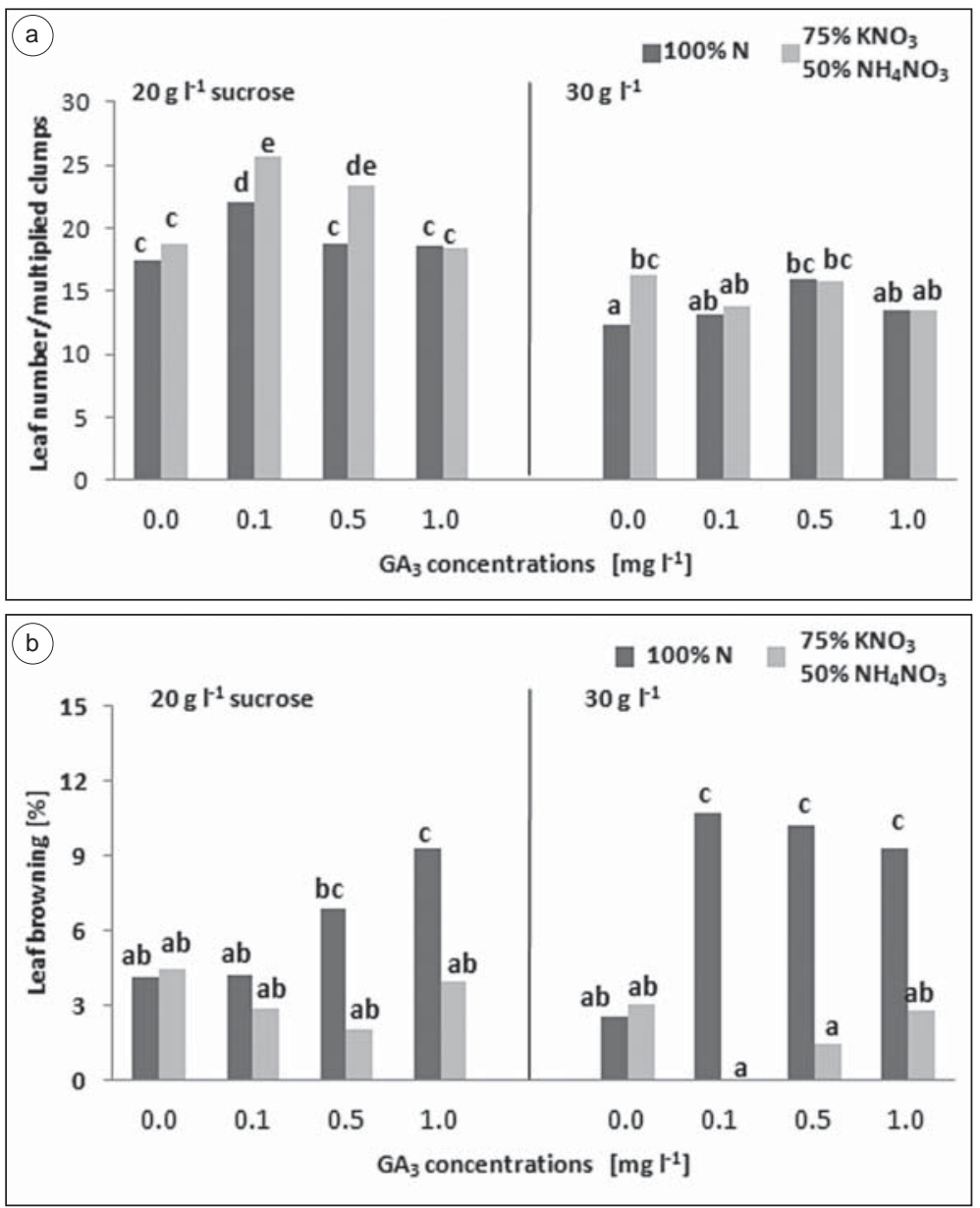

Fig. 2. Effect of $\mathrm{GA}_{3}$, added to MS medium containing $\mathrm{BAP}\left(0.3 \mathrm{mg} \mathrm{l}^{-1}\right)$, different concentrations of sucrose and nitrogen salts on leaf formation (a) and leaf browning (b) in M. × 'Spectrum' after a 5-week subculture period. Means of each growth parameter designated with the same letter do not differ significantly $(\alpha=0.05)$ according to Duncan's test.

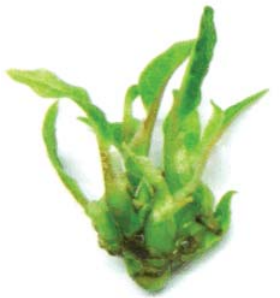

0.0

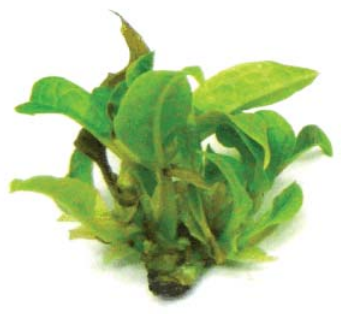

0.1

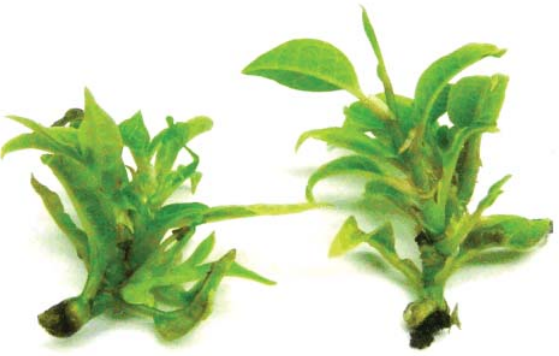

0.5

1.0

Fig. 3. Shoots of $M . \times$ 'Spectrum' after a 5-week subculture period on media containing different concentrations of GA ${ }_{3}$, $0.3 \mathrm{mg} \mathrm{l}^{-1} \mathrm{BAP}, 20 \mathrm{~g} \mathrm{l}^{-1}$ sucrose and reduced levels of nitrogen salts $\left(\mathrm{KNO}_{3} / \mathrm{NH}_{4} \mathrm{NO}_{3 ;}, 75 / 50 \%\right)$. 
tion was partly overcome by exogenous $\mathrm{GA}_{3}$. However, the highest multiplication rate (4.1 shoots/ explants) obtained in the presence of BAP and $\mathrm{GA}_{3}$ $\left(0.5 \mathrm{mg} \mathrm{l}^{-1}\right)$ was decidedly lower than the multiplication rate of the shoots growing on the medium containing $20 \mathrm{~g} \mathrm{l}^{-1}$ sucrose (Fig. 1a). In the presence of $30 \mathrm{~g} \mathrm{l}^{-1}$ sucrose, the GA- stimulation of shoot formation was greater on the medium containing full strength MS nitrogen salts. In general, the application of $\mathrm{GA}_{3}$ did not overcome the sucrose-inhibition of leaf formation in $M$. × 'Spectrum' plantlets, with the exception of the shoots growing in the presence of $0.5 \mathrm{mg} \mathrm{l}^{-1} \mathrm{GA}_{3}$ and reduced levels of nitrogen salts (Fig. 2a). As shown in Fig. 2b, the addition of $\mathrm{GA}_{3}$ to the BAP medium containing full strength nitrogen salts induced leaf browning in $M$. × 'Spectrum' shoots, but its effect depended on the concentration and sucrose level. In the presence of $20 \mathrm{~g} \mathrm{l}^{-1}$ sucrose, the leaf browning was directly proportional to $\mathrm{GA}_{3}$ concentration. On the medium containing $30 \mathrm{~g} \mathrm{l}^{-1}$, however, the rapid increase of leaf browning was observed at the lowest $\mathrm{GA}_{3}$ level $\left(0.1 \mathrm{mg} \mathrm{l}^{-1}\right)$. The GA-induction of leaf browning was the greatest on the medium without cytokinin (data not shown).

\section{SOLUBLE SUGAR CONTENT}

The soluble sugar content in $M . \times$ 'Spectrum' leaves was measured after five weeks of growth on media containing BAP and different concentrations of $\mathrm{GA}_{3}$, sucrose and nitrogen salts in the MS medium. On the control medium (without $\mathrm{GA}_{3}$ ), the soluble sugar content in the shoots was signifi- cantly influenced by high sucrose-to-nitrogen salt ratio (Fig. 4). On the medium with reduced level of nitrogen salts, increasing exogenous sucrose supply (from 20 to $30 \mathrm{~g} \mathrm{l}^{-1}$ ) resulted in $36 \%$ increase of soluble sugar content in magnolia shoots. The addition of $\mathrm{GA}_{3}$ to the BAP medium significantly affected the sugar level in magnolia shoots, but the $\mathrm{GA}_{3}$-mediated effect depended on its concentration and the sucrose/nitrogen salts ratio in the medium (Fig. 4). There was the highest increase in the endogenous sugar level (by $48 \%$ relative to the control) by the applied $\mathrm{GA}_{3}$ at $0.1 \mathrm{mg} \mathrm{l}^{-1}$ to the medium enriched with BAP, $20 \mathrm{~g} \mathrm{l}^{-1}$ sucrose and reduced levels of nitrogen salts $\left(75 \% \mathrm{KNO}_{3}\right.$ and $50 \% \mathrm{NH}_{4} \mathrm{NO}_{3}$ relative to the MS medium). However, increasing $\mathrm{GA}_{3}$ supply (from 0.1 to $1.0 \mathrm{mg} \mathrm{l}^{-1}$ ) lowered the sugar content in magnolias growing on the medium with the reduced nitrogen salts level (irrespective of sucrose concentration in the medium). On the medium with full strength MS nitrogen salts, the addition of $0.1 \mathrm{mg} \mathrm{l}^{-1} \mathrm{GA}_{3}$ together with BAP had no significant effect on the sugar content relative to the control, but increasing $\mathrm{GA}_{3}$ supply (from 0.1 to $1.0 \mathrm{mg} \mathrm{l}^{-1}$ ) enhanced the sugar content in magnolia shoots grown both in the presence of $20 \mathrm{~g} \mathrm{l}^{-1}$ and $30 \mathrm{~g} \mathrm{l}^{-1}$ sucrose (Fig. 4).

\section{ACTIVITY OF ANTIOXIDATIVE ENZYMES}

The activities of antioxidant enzymes in $M . \times$ 'Spectrum' leaves were measured after a fiveweek subculture period. On the control medium containing BAP only, CAT and POD activities were enhanced by lowering the concentration of nitro-

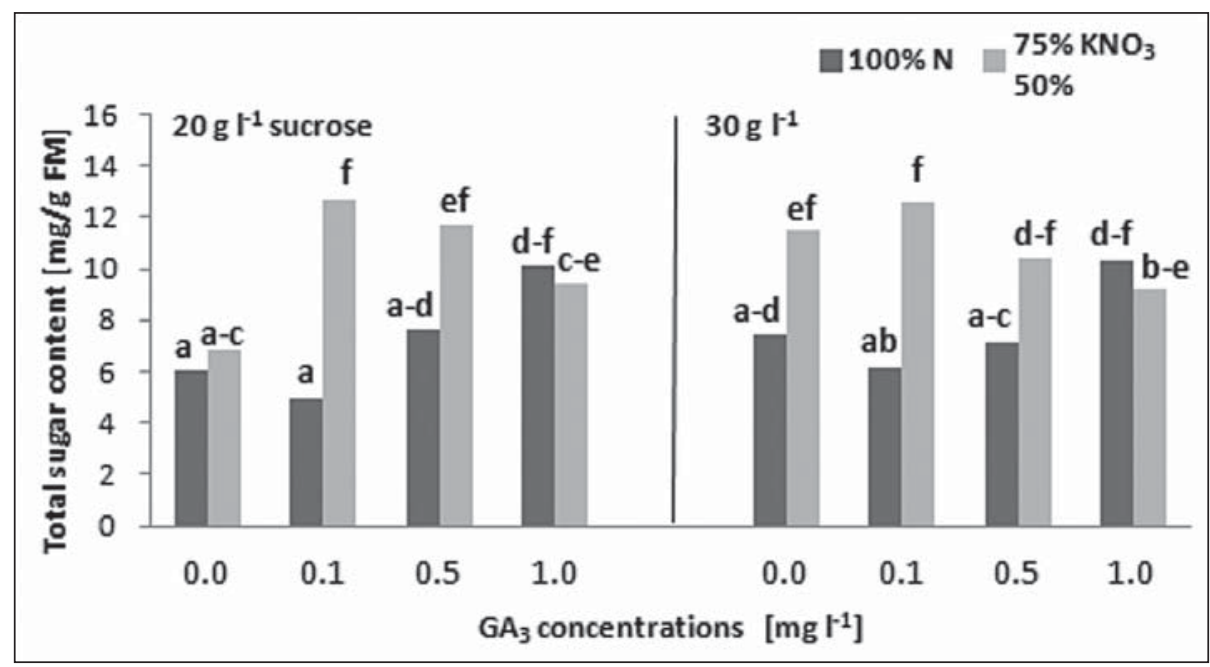

Fig. 4. Effect of $\mathrm{GA}_{3}$, added to MS medium containing BAP $\left(0.3 \mathrm{mg} \mathrm{l}^{-1}\right)$, different concentrations of sucrose and nitrogen salts on the total soluble sugar content in $M . \times$ 'Spectrum' after a 5-week subculture period. Means designated with the same letter do not differ significantly ( $\alpha=0.05)$ according to Duncan's test. 

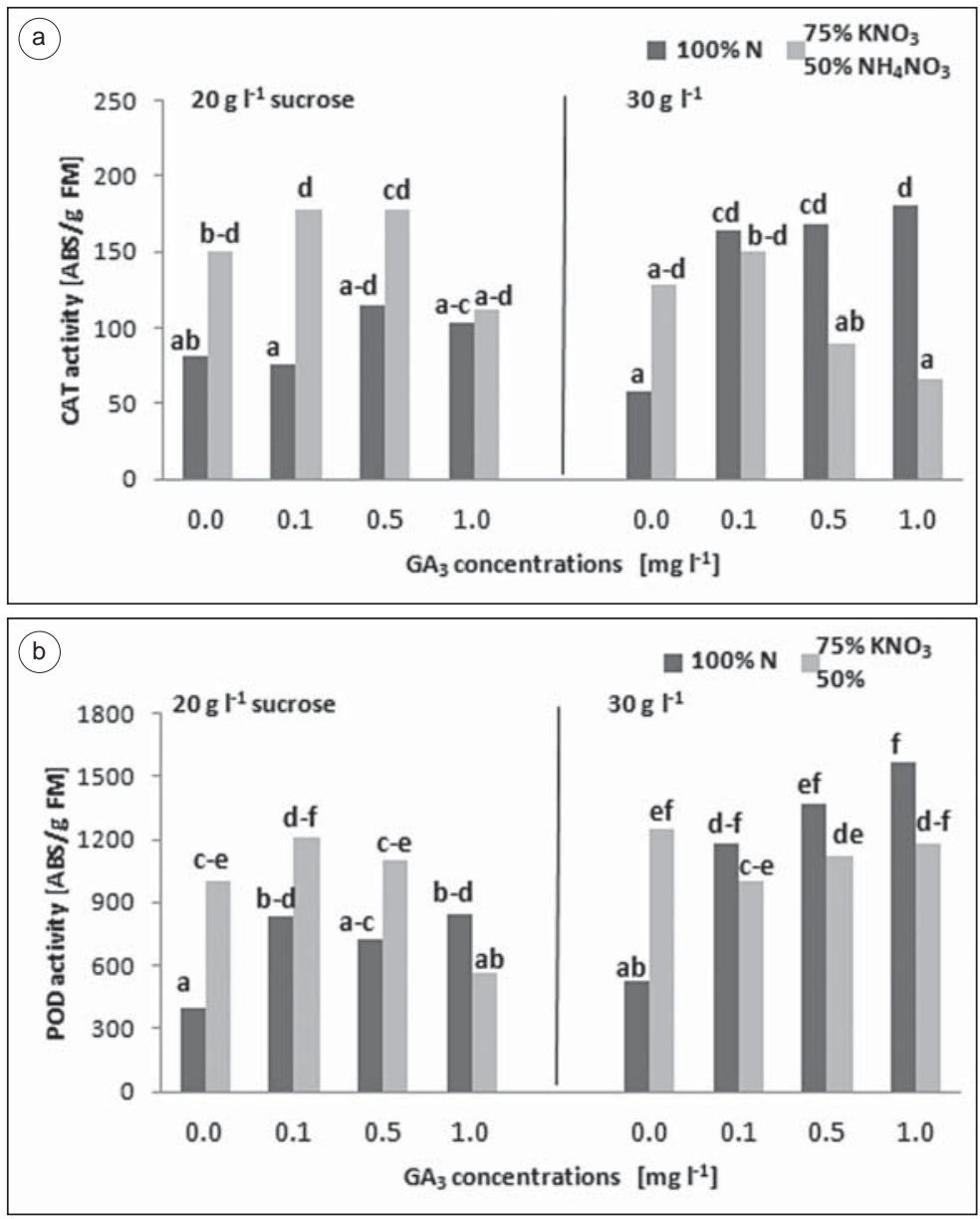

Fig. 5. Effect of $\mathrm{GA}_{3}$, added to MS medium containing BAP $\left(0.3 \mathrm{mg} \mathrm{l}^{-1}\right)$, different concentrations of sucrose and nitrogen salts on the catalase (a) and peroxidase (b) activities in $M . \times$ 'Spectrum' after a 5-week subculture period. Means of each growth parameter designated with the same letter do not differ significantly $(\alpha=0.05)$ according to Duncan's test.

gen salts in the MS medium (Fig. 5a and 5b). Irrespective of the sucrose levels, the reduced level of nitrogen salts $\left(75 \% \mathrm{KNO}_{3}\right.$ and $50 \% \mathrm{NH}_{4} \mathrm{NO}_{3}$ ) enhanced CAT activity by $50 \%$ and POD activity by $60 \%$ relative to the medium containing $100 \% \mathrm{MS}$ nitrogen salt levels. The application of $\mathrm{GA}_{3}$ together with BAP significantly affected the antioxidant enzyme activities in $M$. × 'Spectrum' shoots, but the effect of $\mathrm{GA}_{3}$ depended on its concentration and the levels of sucrose and nitrogen salts ratio in the medium (Fig. $5 \mathrm{a}$ and $5 \mathrm{~b}$ ). On the medium supplemented with $20 \mathrm{~g} \mathrm{l}^{-1}$ sucrose, $\mathrm{GA}_{3}$ had not significant influence on CAT activities, irrespective of the nitrogen levels. On the medium containing $30 \mathrm{~g} \mathrm{l}^{-1}$ sucrose, $\mathrm{GA}_{3}$ (regardless of concentration) significantly enhanced (by 65\%) CAT activities in the presence of full strength MS nitrogen salts. On the medium with reduced levels of nitrogen salts, increasing $\mathrm{GA}_{3}$ concentration from 0.1 to $1.0 \mathrm{mg} \mathrm{l}^{-1}$ decreased CAT activities, but the differences were not statistically important (Fig. 5a). As shown in Fig. 5b, the highest increase in POD activity (by $70 \%$ ) was stimulated by $\mathrm{GA}_{3}$ (in a concentrationdependent manner) on the medium containing high levels of sucrose and nitrogen salts. The promoting effect of $\mathrm{GA}_{3}$ on CAT and POD activities on the medium containing high levels of sucrose and nitrogen salts coincided with the enhanced shoot formation capacity of $M . \times$ 'Spectrum' in vitro. In the presence of $20 \mathrm{~g} \mathrm{l}^{-1}$ sucrose, significant increase in activity of POD was observed when $0.1 \mathrm{mg} \mathrm{l}^{-1} \mathrm{GA}_{3}$ was added to the medium with reduced levels of nitrogen salts and 0.1 and $1.0 \mathrm{mg} \mathrm{l}^{-1} \mathrm{GA}_{3}$ to the medium containing full strength MS nitrogen salts. Enhanced POD activity observed on the medium with the reduced levels of sucrose and nitrogen salts coincided with the highest rate of shoot formation in $M . \times$ 'Spectrum' in vitro. 


\section{DISCUSSION}

Gibberellins (GAs) play a key role in the control of cell division, elongation and the correlative inhibition phenomenon (Horvath et al., 2002; Zhang et al., 2008). In plants propagated in vitro, addition of $\mathrm{GA}_{3}$ to the medium has been found to stimulate (Beretta and Eccher, 1987; Gabryszewska, 2009; Wojtania et al., 2011) or inhibit (Sujatha and Reddy, 1998; Fraguas et al., 2004) lateral bud outgrowth. The increased rate of shoot formation was usually a result of a combined treatment with $\mathrm{GA}_{3}$, cytokinin and sucrose (Gabryszewska, 2009, 2015; Wojtania et al., 2011). Like in other plant species, the shoots of $M . \times$ 'Spectrum' treated with $\mathrm{GA}_{3}$ only had no capacity for shoot formation, and additionally leaf browning was observed (data not shown). In the case of magnolia, the highest rate of shoot formation was found on the medium containing a low level of $\mathrm{GA}_{3}\left(0.1 \mathrm{mg} \mathrm{l}^{-1}\right)$. However, the optimal $\mathrm{GA}_{3}$ level for increasing axillary multiplication was found to vary between genotypes. For example, it was $10 \mathrm{mg} \mathrm{l}^{1^{-1}}$ in Paeonia lactiflora (Gabryszewska, 2009), 0.7-1.0 $\mathrm{mg} \mathrm{l}^{-1}$ in Camelia japonica (Beretta and Eccher, 1987; Wojtania et al., 2011) and $0.1-0.5 \mathrm{mg}^{-1}$ in various wild rose species (Pawłowska, 2011).

The results presented in this paper demonstrate that both the morphological and biochemical responses to $\mathrm{GA}_{3}$ significantly depended on the levels of sucrose and nitrogen salts in the medium. The amounts of sucrose and nitrogen salts and their ratio in the media were found to be an important factor regulating formation of shoots of different plant species propagated in vitro, including Syringa vulgaris and Helleborus niger (Gabryszewska, 2011, 2015). The high concentration of sucrose inhibited the outgrowth of axillary buds and development of Peonia lactiflora propagated in vitro but exogenous gibberellins can overcome the sugar-induced inhibition and stimulate shoot formation and growth in the presence of cytokinins (Gabryszewska, 2009). In the case of $M$. × 'Spectrum', however, $\mathrm{GA}_{3}$ partly overcame the sucrose-induced inhibition of the shoot formation but not the leaf formation.

The present study indicates that Magnolia shoots treated with $\mathrm{GA}_{3}$ contain more soluble sugar and show higher activity of antioxidant enzymes, relative to the control. It has been reported that GA treatments led to an increase in sugar content in different plant species, including Phalaenopsis amabilis and Rosa hybrida that correlated with floral initiation (Chen et al., 1994) and shoot branching (Choubane et al., 2012). In M. × 'Spectrum', the highest increase in the soluble sugar content was observed when $0.1 \mathrm{mg} \mathrm{l}^{-1} \mathrm{GA}_{3}$ was added to the BAP medium with $20 \mathrm{~g}^{1^{-1}}$ sucrose and reduced lev- els of nitrogen salts $\left(75 \% \mathrm{KNO}_{3}\right.$ and $50 \% \mathrm{NH}_{4} \mathrm{NO}_{3}$ relative to the MS medium). In this case, the enhanced sugar content coincided with the highest rate of shoot formation. On the other hand, increased sugar content was also observed in the shoots growing on $\mathrm{GA}_{3}$-free medium supplemented with BAP, $30 \mathrm{~g} \mathrm{l}^{-1}$ sucrose and reduced amounts of nitrogen salts. It could be related to the accumulation of different soluble sugars in $M . \times$ 'Spectrum' shoots. The available evidence suggests that some processes may be mediated by the absolute levels of a particular sugar, such as glucose or sucrose, whereas other ones by flux through particular sugars (Gibson, 2003). A relationship between sugar availability and bud outgrowth has been reported for different plant species, including Rosa hybrida (Barbier et al., 2015). In this process, sucrose was suggested not only to play a trophic role, but also to act as a signaling molecule (Barbier et al., 2015).

High levels of both sugar and nitrogen have been found to be inhibitory to GAs production and responsiveness (Candau et al., 1992; Perata et al., 1997). It has been demonstrated that many magnolia genotypes prefer media containing a lower nitrogen concentration than that of MS medium (Biedermann, 1987; Kamenicka and Lanakova, 2000; Wojtania et al., 2015). It is believed that magnolia shoots growing on media containing low levels of sucrose and/or low levels of nitrogen salts may contain higher levels of endogenous GAs required for enhanced shoot formation in magnolia in vitro. Accumulation of GAs in vegetative buds has been shown to promote the shift from meristematic identity to organ differentiation (Dodsworth, 2009).

GAs are also known to alter plant metabolism under stress conditions (Iqbal et al., 2011). In some plant species, including Cucumis sativus and Lycopersicon esculentum, it has been shown that the $\mathrm{GA}_{3}$-improved stress tolerance correlates with enhanced activity of antioxidant enzymes ( $\mathrm{Li}$ et al., 2011; Khavari-Nejad et al., 2013). In other plants, such as Vigna radiata and Zea mays, $\mathrm{GA}_{3}$ treatments reduced the activities of antioxidant enzymes (Chakrabarti and Mukharji, 2003; Tuna et al., 2008). As shown in our study, the addition of $\mathrm{GA}_{3}$ to the BAP medium stimulated or inhibited CAT and POD activities in magnolia shoots depending on the levels of sucrose and nitrogen salts in the medium. The highest increase in CAT and POD activities was observed after the addition of $\mathrm{GA}_{3}$ to the medium containing high levels of sucrose and nitrogen salts.

The results presented here showed the importance of interaction between $\mathrm{GA}_{3}$, sucrose and nitrogen in the morphological and biochemical responses of $M . \times$ 'Spectrum' plantlets in vitro. For the first time, it has been found that $\mathrm{GA}_{3}$-enhanced shoot formation in magnolia in vitro coincided with 
enhanced content of soluble sugar and antioxidant enzyme activities. It is suggested that the shoot formation response to $\mathrm{GA}_{3}$ may be related to accumulation of a specific kind of sugar, but it needs further study. The improved shoot formation capacity obtained after the addition of $\mathrm{GA}_{3}$ at $0.1 \mathrm{mg} \mathrm{l}^{-1}$ and $0.5 \mathrm{mg} \mathrm{l}^{-1}$ to a BAP medium containing $20 \mathrm{~g} \mathrm{l}^{-1}$ sucrose and reduced levels of nitrogen salts $(75 \%$ $\mathrm{KNO}_{3}$ and $50 \% \mathrm{NH}_{4} \mathrm{NO}_{3}$ ) can be very useful for mass propagation of $M$. $\times$ 'Spectrum' in vitro.

\section{AUTHORS' CONTRIBUTIONS}

AW - designed and performed the experiments, analyzed data and wrote the paper; ES - was responsible for the plant tissue analysis; EG - critically read and revised the manuscript. The authors declare that there are no conflicts of interest.

\section{ACKNOWLEDGEMENTS}

This research was supported by the Polish Ministry of Science and Higher Education as part of the statutory activities (7.2.3) of the Department of General Biology, Research Institute of Horticulture in Skierniewice.

\section{REFERENCES}

AEBI H. 1984. Catalase in vitro. Methods in Enzymology 105: 121-125.

BARBIER FF, LunN JE, and BEVERIDGe CA. 2015. Ready, steady, go! A sugar hit starts the race to shoot branching. Current Opinion in Plant Biology 25: 39-45.

BIEDERMANN IEG. 1987. Factors affecting establishment and development of magnolia hybrids in vitro. Acta Horticulturae 212: 625-629.

BEREtTA D, and ECCHER T. 1987. Determination of optimal level of BAP, $\mathrm{GA}_{3}$ and IAA in micropropagation of Camellia by an orthogonal composite design. Acta Horticulturae 212: 151-154

Candau R, Avalos J, and Cerdá-Olmedo E. 1992. Regulation of gibberellins biosynthesis in Gibberella fujikuroi. Plant Physiology 100: 1184-1188.

Chae WS, Serpe MD, Anderson JV, Gesh RW, and Horvath DP. 2006. Sugars, hormones, and environment affect the dormancy status in underground buds of leafy spurge (Euphorbia esula). Weed Science 54: 59-68.

Chakrabarti N, and MukHARJI S. 2003. Alleviation of $\mathrm{NaCl}$ stress by pretreatment of phytohormones in Vigna radiata. Biologia Plantarum 46: 589-594.

Chen WS, Liu HY, LiU ZH, Yang L, and Chen WH. 1994. Gibberellin and temperature influence carbohydrate content and flowering in Phalaenopsis. Physiologia Plantarum 90: 391-395.
Choubane D, Rabot A, Mortreau E, Legourrierec J, Peron T, Foucher F, Ahcene Y, Pelleschi-Travier S, Leduc N, HAMAMA L, and SAKR S. 2012. Photocontrol of bud burst involves gibberellins biosynthesis in Rosa sp. Journal of Plant Physiology 169: 1271-1280.

DoDsworth SA. 2009. A diverse and intricate signaling network regulates stem cell fate in the shoot apical meristem. Developmental Biology 336: 1-9.

Dubois M, Gilles KA, Hamilton JK, Roberts PA, and Smith F. 1956. Colorimetric method for determination of sugars and related substances. Analytical Chemistry 28: 350-356.

Dun EA, de Saint Germain A, Rameau C, and Beveridge CA. 2012. Antagonistic action of strigolactone and cytokinin in bud outgrowth control. Plant Physiology 158: 487-498.

Fraguas CB, Pasgual M, Dutra LF, and Cazetta JO. 2004. Micropropagation of fig (Ficus carica L.) 'Roxo de Valinhos' plants. In Vitro Cellular and Developmental BiologyPlant 40: 471-474.

GABRYSZEWSKA E. 2009. Rola regulatorów wzrostu, węglowodanów, soli mineralnych, glutationu i temperatury w rozmnażaniu in vitro piwonii chińskiej. Zeszyty Naukowe Instytutu Sadownictwa i Kwiaciarstwa, Monografie i rozprawy. (in Polish with English abstract).

GABRYSZEWSKA E. 2011. Effect of various levels of sucrose, nitrogen salts and temperature on the growth and development of Syringa vulgaris L. shoots in vitro. Journal of Fruit and Ornamental Plant Research 19: 133-148.

GABRYSZEWSKA E. 2015. Effect of different sucrose and nitrogen salts levels in the medium and temperature on in vitro propagation of Helleborus niger L. Acta Arobotanica 68: 161-171.

GiBson SI. 2003. Sugar and phytohormone response pathways: navigating a signaling network. Journal of Experimental Botany 55: 253-264.

HORVATH DP, CHAO WS, and ANDERSON JV. 2002. Molecular analysis of signals controlling dormancy and growth in underground adventitious buds of leafy spurge (Euphorbia esula L.). Plant Physiology 128: 1439-1446.

IgBal N, Nazar R, IgBal M, Khan R, Masood A, and Khan NA. 2011. Role of gibberellins in regulation of source-sink relations under optimal and limiting environmental conditions. Current Science 100: 998-1007.

Kamenicka A, and LanaKova M. 2000. Effect of medium composition and type of vessel closure on axillary shoot production of magnolia in vitro. Acta Physiologiae Plantarum 22: 129-134.

KHAVARI-NEJAD RA, NAJAFI F, and RANJBARI M. 2013. The effects of $\mathrm{GA}_{3}$ application on growth, lipid peroxidation, antioxidant enzymes activities, and sugars levels of cadmium stressed tomato (Lycopersicon esculentum Mill. Cv. $\mathrm{CH}$ ) plants. Romanian Journal of Biology Plant Biology 58: 51-60.

LI Q, Li CH, YU X, and SHI Q. 2011. Gibberellin $\mathrm{A}_{3}$ pretreatment incresed antioxidative capacity of cucumber radicles and hypocotyls under suboptimal temperature. African Journal of Agricultural Research 6: 4091-4098.

LüCK H. 1962. Methoden der enzymatischen Analyse. (Ed. H.U. Bergmeyer) Verlag Chemie, GmbH Weinheim 895-897. 
Mitrović A, JANošEvić D, Budimir S, and Pristov JB. 2012. Changes in antioxidative enzymes activities during Tacitus bellus direct shoot organogenesis. Biologia Plantarum 56: 357-361.

Murashige T, and Skoog F. 1962. A revised medium for rapid growth and bioassays with tobacco tissue cultures. Physiologia Plantarum 15: 473-497.

MÝtinová Z, Motyka V, Haisel D, Lubovská Z, TrávničKová A, Dobrev P, HoliK J, and Wilhelmová N. 2011. Antioxidant enzymatic protection during tobacco leaf ageing is affected by cytokinin depletion. Plant Growth Regulation 65: $23-34$.

Parris JK, Touchel DH, Ranney TG, and Adelberg J. 2012. Basal salt composition, cytokinins, and phenolic binding agents influence in vitro growth and ex vitro establishment of Magnolia 'Ann'. HortScience 47: 1625-1629.

PawŁowska B. 2011. The effect of BAP and $\mathrm{GA}_{3}$ on the shoot multiplication of in vitro cultures of Polish wild roses. Folia Horticulturae 23(2): 145-149.

Perata P, Matsukura C, Vernieri P, and Yamaguchi J. 1997. Sugar repression of a gibberellin-dependent signaling pathway in barley embryos. Plant Cell 9: 2197-2208.

Podwyszyńska M, WoJTAnia A, and Gabryszewska E. 2000. Application of m-topolin for plant propagation. Zeszyty Naukowe Instytutu Sadownictwa i Kwiaciarstwa 7: 173-180. (in Polish with English abstract).

SAHOO Y, and CHAND PK. 1998. Micropropagation of Vitex negundo L., a woody aromatic medicinal shrub, through high-frequency axillary shoot proliferation. Plant Cell Reports 18: 301-307.
Sokolov RS, Atanassova BY, and Iakimova ET. 2014. Physiological response of in vitro cultured Magnolia sp. to nutrient medium composition. Journal of Horticultural Research 22: 49-61.

Sujatha M, and RedDy TP. 1998. Differential cytokinin effects on the stimulation of in vitro shoot proliferation from meristematic explants of castor (Ricinus communis L.). Plant Cell Reports 17: 561-566.

TANG W, and Newton RJ. 2005. Peroxidase and catalase activities are involved in direct adventitious shoot formation induced by thidiazuron in eastern white pine (Pinus strobus L.) zygotic embryos. Plant Physiology and Biochemistry 43: 760-769.

Tuna AL, Kaya C, Dikilitas M, and Higgs D. 2008. The combined effects od gibberellic acid and salinity on same antioxidant enzyme activities, plant growth parameters and nutritional status in maize plants. Environmental and Experimental Botany 62: 1-9.

Wojtania A, Gabryszewska E, and PodwyszyńsKa M. 2011. The effect of growth regulators and sucrose concentration on in vitro propagation of Camellia japonica L. Propagation of Ornamental Plants 11: 177-183.

WOJTANiA A, and SKRZYPEK E. 2014. Effects of cytokinins on antioxidant enzymes in in vitro grown shoots of Pelargonium hortorum L. H. Bayley. Acta Agrobotanica 67: 33-42.

WoJTANia A, SKrZYPEK E, and GabryszewSKa E. 2015. Effect of cytokinin, sucrose and nitrogen salts concentrations on the growth and development and phenolics content in Magnolia $\times$ soulangiana 'Coates' shoots in vitro. Acta Scientiarum Polonorum- Hortorum Cultus 14: 51-62.

ZHANG X, Wu Z, and HuANG C. 2008. Effects of gibberellins on in vitro shoot bud regeneration of Arabidopsis. African Journal of Biotechnology 7: 4159-4163. 